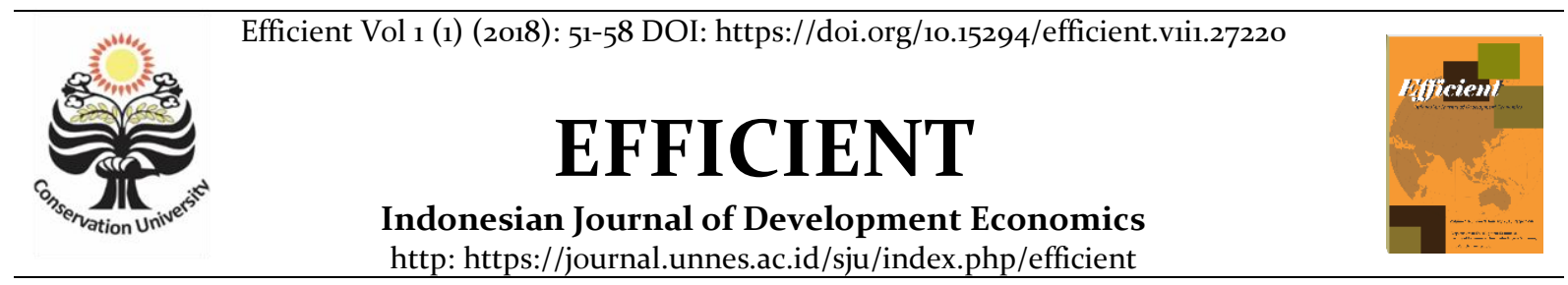

\title{
Strategi Pengembangan Kerjasama Sister City Kota Semarang, Indonesia - Brisbane, Australia
}

\author{
Nadia Damayanti ${ }^{\bowtie}$ \\ Jurusan Ekonomi Pembangunan,Fakultas Ekonomi, Universitas Negeri Semarang \\ Permalink/DOI: https://doi.org/10.15294/efficient.vii1.27220
}

Received: July 2017; Accepted: October 2017; Published: January 2018

\begin{abstract}
The aim of this research is to know whether there are internal and external factors of Semarang City Government and to look for the most sutable strategy that could be perform in Sister City Semarang - Brisbane. The primary data were gathered by using questionnaire and interviewing experts who understand about Sister City. The secondary data were taken from books, scientific journal, and earlier research. The data retrieval methods are interview, observation, documentation, library studies, and questionnaire. The analytic tools that being used in this research is SWOT analysis and descriptive analysis. There are external and internal factors that could influence from the strength perspective is education and science technology scope of Semarang. From weakness perspective is spoken-written English of Semarang Government's staffs. From opportunity perspective is increasing development chances of human resources and more cooperation such as student exchange, cooperation between both countries. From threat perspective is the loose relationship between both Government of Indonesia and Australia The citizens of Semarang City also need to take action in the matter of Sister City. By taking action, there will be some kind of continuity of Sister City of Semarang City and Brisbane City, of course still with Semarang City Government intervention.
\end{abstract}

Keywords: Brisbane; Partnership; Sister City; Strategy; SWOT Analysis

\begin{abstract}
Abstrak
Tujuan penelitian yaitu untuk melihat faktor eksternal dan faktor internal Pemerintah Kota Semarang serta strategi yang tepat untuk kerjasama Sister City Kota Semarang - Kota Brisbane. Data primer diambil dengan wawancara dan kuesioner kepada ahli yang menangani bidang kerjasama Sister City. Data sekunder diambil dari buku, penelitian terdahulu, dan jurnal. Metode pengambilan data yaitu wawancara, observasi, dokumentasi, studi kepustakaan, dan angket. Analisis penelitian menggunakan analisis SWOT dan analisis Deskriptif. Berdasarkan hasil penelitian bahwa faktor eksternal dan faktor internal yang mempengaruhi yaitu dari sisi kekuatan pada faktor internal merupakan dari bidang pendidikan dan IPTEK Kota Semarang. Sisi kelemahan yaitu kemampuan staf berbahasa Inggris Pemerintah Kota Semarang. Sisi Peluang dari faktor eksternal yaitu peningkatan SDM dan kesempatan berupa kerjasama, dan pertukaran pelajar. Sisi ancaman yaitu hubungan Pemerintah Indonesia dengan Pemerintah Australia yang sempat renggang. Saran yaitu masyarakat dan pengusaha sebaiknya ikut terlibat dalam kerjasama Sister City. Adanya keterlibatan masyarakat dalam kerjasama Sister City dapat menciptakan keberlangsungan kerjasama dan tentunya dalam pengawasan pemerintah.
\end{abstract}

\section{Kata Kunci: : Analisis SWOT; Brisbane; Kerjasama; Semarang; Sister City; Strategi}

How to Cite: Damayanti, N. (2018). Strategi Pengembangan Kerjasama Sister City Kota Semarang, Indonesia Brisbane, Australia. EFFICIENT Indonesian Journal of Development Economics, 1(1), 52-58. https://doi.org/10.15294/efficient.vii.27220

(C) 2018 Universitas Negeri Semarang. All rights reserved

\footnotetext{
Alamat Korespondensi :

Alamat: Gedung L2 Lantai 2 FE Unnes

Kampus Sekaran, Gunungpati, Semarang, 50229

E-mail : jurnalefficient@gmail.com
} 


\section{PENDAHULUAN}

Sebagai sebuah bangsa yang memiliki tujuan nasional seperti pada umumnya perlu merealisasikan tujuan nasional tersebut. Secara demokratis, pembangunan berlangsung sendiri berdasarkan kemauan, kebutuhan, dan kemampuan rakyat, kemudian dilakukan sendiri oleh rakyat. Pemerintah Pusat tidak akan terlepas dengan peran Pemerintah Daerah. Indonesia merupakan negara kepulauan yang terdiri dari 34 provinsi dan masing-masing provinsi mempunyai fungsi tersendiri dalam menjalankan pemerintahan daerah. Dalam kegiatan pertumbuhan ekonomi, pemerintah dapat melakukan beberapa gebrakan guna memajukan pertumbuhan ekonomi. Otonomi daerah memberikan kewenangan pada Pemerintah Daerah dalam mengatur Tata Kelola Ekonomi Daerah (TKED). Guna mengedepankan fungsi tata kelola daerah dalam mencapai daya saing daerah, diperlukan adanya kerjasama yang baik antara pemerintah, masyarakat, dan stakeholder daerah masing-masing.

Kegiatan yang menyejahterakan rakyat dalam hal ini salah satunya yaitu melalui kegiatan kerjasama. Kerjasama yang terjalin sudah merupakan sebuah rancangan yang matang dari Pemerintah Daerah. Kerjasama dan kebijakan publik yang baik akan menghasilkan sesuatu yang bermanfaat sesuai dengan tujuan pada saat sebuah kebijakan tersebut dibangun. Kerjasama merupakan kegiatan atau usaha yang dilakukan oleh beberapa orang (lembaga, pemerintah, dan sebagainya) untuk mencapai tujuan bersama.

Kerjasama luar negeri merupakan salah satu kerjasama yang dapat dilakukan oleh Pemerintah Daerah guna meningkatkan daya saing daerah. Kerjasama Sister City merupakan kerjasama yang diselenggarakan antara kedua kota yang memiliki visi untuk meningkatkan kesejahteraan masyarakat yang hidup di dua kota tersebut. Bentuk-bentuk kerjasama Pemerintah Daerah dengan Pemerintah Luar Negeri dapat berupa kerjasama provinsi dan kabupaten/kota "kembar"; kerjasama teknik termasuk bantuan kemanusiaan; kerjasama penyertaan modal; dan kerjasama lainnya sesuai dengan peraturan perundangan (Sekretariat Daerah Provinsi Jawa Tengah, 2008). Hal yang mendasari kerjasama Sister City bahwa dua kota saling bekerjasama untuk sesuatu yang spesifik seperti mempromosikan perdamaian, persahabaran, dan memahami masyarakat dari kedua negara (BellSouder \& Bredel, 2005).

Pemerintah Kota Semarang memiliki beberapa mitra kerjasama Sister City yaitu dengan Pemerintah Kota Brisbane, Australia, Pemerintah Kota Beihai, Cina, Pemerintah Fuzhou, Cina, Pemerintah Kota Jung-gu, Korea Selatan dan Pemerintah Kota Split, Kroasia. Dalam Rancangan Pembangunan Jangka Menengah Daerah tahun 2010-2015 Kota Semarang salah satunya yaitu mewujudkan pemerintahan yang efisen dan efektif, meningkatkan pelayanan publik, serta menjunjung tinggi supremasi hukum meliputi penguatan otonomi daerah.

Permasalahan kerjasama Sister City Kota Semarang - Brisbane yaitu ada tidaknya faktor internal dan faktor eksternal dari pemberhentian kerjasama Sister City serta rumusan strategi yang tepat untuk kerjasama Sister City Kota Semarang - Kota Brisbane.Tujuan penelitian dilakukan untuk melihat faktor internal dan eksternal yang dapat mempengaruhi pemberhentian kerjasama Sister City Kota Semarang - Kota Brisbane, serta strategi yang tepat untuk mengembangkan kerjasama Sister City Kota Semarang - Kota Brisbane. 


\section{METODE PENELITIAN}

Dasar penelitian dilakukan dengan wawancara dan pengisian kuesioner kepada beberapa narasumber yang terlibat dalam kerjasama Sister City Kota Semarang - Kota Brisbane. Narasumber (keypeople) diambil dari Pemerintah Kota Semarang, Bappeda Kota Semarang, Dinas Kebudayaan dan Pariwisata Kota Semarang, dan Pemerintah Kota Brisbane.

Jenis data yang digunakan berupa data primer dan data sekunder. Data primer diperoleh dari wawancara dan pengision kuesioner oleh pihak terkait kerjasama Sister City. Data sekunder diperoleh melalui buku, majalah, jurnal, dan peta. Sumber data primer yaitu narasumber terkait kerjasama Sister City yaitu Nik Sutiyani dari Bappeda Kota Semarang, Dhamyantie Savitrie dari Sekretariat Daerah Kota Semarang bagian Kerjasama, Taufan Yuristian dari Dinas Kebudayaan dan Pariwisata Kota Semarang, serta Garth Henderson dari Pemerintah Kota Brisbane bagian penanganan khusus kerjasama Sister City.

Metode pengumpulan data dilakukan dengan wawancara, observasi, studi kepustakaan, dokumentasi, dan angket/kuesioner. Wawancara dilakukan tatap muka secara langsung dengan perwakilan dari Bappeda Kota Semarang, Dinas Kebudayaan dan Pariwisata Kota Semarang, dan Sekretariat Daerah Kota Semarang. Wawancara juga dilakukan menggunakan email dengan perwakilan dari Pemerintah Kota Brisbane. Observasi dilakukan dengan mengamati kegiatan yang ada di Sekretariat Daerah Kota SemarangMetode analisis data yaitu menggunakan analisis SWOT dan analisis deskriptif. Analisis SWOT digunakan untuk menentukan strategi pengembangan kerjasama
Sister City Kota Semarang - Kota Brisbane. Pengolahan data mentah berupa angka dilakukan dengan menggunakan Excel yang kemudian diterjemahkan menjadi sesuatu yang mudah dipahami pembaca dengan menggunakan analisis deskriptif. Prinsip dasar dalam menjalankan analisis SWOT ada dua menurut yaitu menilai posisi strategi lembaga berhadapan dengan lingkungan eksternal lembaga yang dapat mempengaruhi misi dan strategi lembaga (Kearns, 1992). Menurut Kearns, analisis SWOT lebih baik dilakukan dengan menganalisis faktor eksternal (peluang dan ancaman) terlebih dahulu daripada faktor internal (kekuatan dan kelemahan), logisnya karena organisasi maupun lembaga harus merespon faktor eksternal, bukan sebaliknya (Espy, 1986). Tahapan analisis yang digunakan yaitu analisis EFAS, IFAS, Matrik Internal -Eksternal, Analisis Matrik SWOT, dan formulasi strategi.

\section{HASIL DAN PEMBAHASAN}

Faktor pendorong dan faktor penghambat merupakan salah satu sisi penting dalam penelitian ini. Faktor pendorong dan penghamabat kerjasama Sister City Kota Semarang -Faktor pendorong dan penghambat digunakan sebagai acuan untuk melakukan analisis dan perumusan strategi. Dari faktor pendorong dan penghambat tersebut diolah menggunakan alat analisis SWOT untuk memformulasikan strategi untuk kerjasama Sister City Kota Semarang - Kota Brisbane. Faktor pendorong dan penghambat kerjasama Sister City diperoleh dari faktor internal dan eksternal dalam kerjasama Sister City Kota Semarang Kota Brisbane yaitu kekuatan, kelemahan, peluang, dan ancaman. Kekuatan dari kerjasama Sister City Kota Semarang - Kota Brisbane yaitu 
dukungan penuh pemerintah Kota Semarang, ruang lingkup kerjasama yang luas, bidang pariwisata dan kebudayaan Kota Semarang yang potensial, dukungan dari stakeholder, sarana dan prasaran Kota Semarang yang memadai, bidang IPTEK dan pendidikan Kota Semarang yang potensial, serta bidang pembangunan perkotaan dan lingkungan hidup Kota Semarang yang potensial. Kelemahan dari kerjasama Sister City Kota Semarang - Kota Brisbane yaitu pendanaan APBD yang kurang untuk kerjasama Sister City, perubahan peraturan otonomi daerah, pergantian pemimpin, pergantian peraturan, informasi publik Kota Semarang yang kurang mengenai kerjasama Sister City di Kota Semarang, kemampuan Bahasa Inggris staf Pemerintah Kota Semarang, dan birokrasi satu pintu yang belum efektif.

Peluang dari kerjasama Sister City Kota Semarang - Kota Brisbane yaitu membuka hubungan dan networking internasional, saling tukar menukar informasi, peningkatan kualitas SDM, membuka akses kebudayaan dan pariwisata, membuka akses IPTEK dan pendidikan, serta masuknya tawaran baik berupa kegiatan kerjasama, studi banding, dan pertukaran pelajar. Ancaman dari kerjasama Sister City Kota Semarang - Kota Brisbane yaitu hubungan politik Indonesia - Australia yang sempat renggang, wabah flu burung tahun 2003, munculnya travel warning setelah bom bali 2002, dan adanya krisis moneter di tahun 1998.

Alur alat analisis SWOT yang pertama yaitu analisis EFAS. Pembobotan dan rating faktorfaktor eksternal (peluang dan ancaman) kerjasama Sister City Kota Semarang - Kota Brisbane yang sudah dilakukan diproses menggunakan software Microsoft Excel. Output yang diperoleh yaitu bahwa peluang yang paling besar yang dapat diraih dari kerjasama Sister City
Kota Semarang - Kota Brisbane yaitu peningkatan kualitas SDM dan ancaman tertinggi dari kerjasama Sister City Kota Semarang - Kota Brisbane yaitu hubungan politik Indonesia Australia yang sempat renggang.

Peluang terbesar dari kerjasama Sister City Kota Semarang - Kota Brisbane yaitu peningkatan kualitas SDM. Dalam kerjasama Sister City Kota Semarang - Kota Brisbane peningkatan kualitas SDM dilakukan dengan pertukaran staf kedua Pemerintahan, serta pertukaran pendidikan dan kebudayaan yang berlanjut. Minimal ada empat pokok upaya peningkatan SDM menurut (Djojohadikusumo, 1991) yaitu: Peningkatan kualitas hidup yang meliputi baik kualitas manusia seperti jasmani, rohani, dan kejuangan, maupun kualitas kehidupannya seperti perumahan dan pemukiman yang sehat, Peningkatan kualitas SDM yang produktif dan upaya pemerataan penyebarannya, Peningkatan kualitas SDM yang berkemampuan dalam memanfaatkan, mengembangkan dan menguasai IPTEK yang berwawasan lingkungan, serta Pengembangan pranata yang meliputi kelembagaan dan peran hukum yang mendukung upaya peningkatan kualitas SDM.

Ancaman dari kerjasama Sister City Kota Semarang - Kota Brisbane yaitu hubungan politik antara Indonesia dengan Australia yang sempat renggang. Hubungan kedua negara dapat sangat akrab seperti pada masa pemerintahan Presiden Soeharto dan Perdana Menteri Paul Keating tahun 1992 - 1995, dan mudah menegang seperti pada pemerintahan Presiden B.J Habibie dan Perdana Menteri John Howard, atau di era Presiden Susilo Bambang Yudhoyono dan Perdana Menteri Tony Abbott 2013 - 2014 (Mar'iyah, 2005). Kekhawatiran Australia akan munculnya "Islam Ekstremis" seperti Al-Qaeda 
dan Jamaah Islamiyah, serta permasalahan Papua Barat sempat mengganggu hubungan Indonesia dengan Australia (Setyawati \& Agussalim, 2015).

Alur kedua dalam analisis SWOT yaitu analisis IFAS. Analisis IFAS merupakan analisis yang digunakan untuk mencari faktor internal yang paling menonjol dalam kegiatan kerjasama Sister City Kota Semarang - Kota Brisbane. Output yang diperoleh dari perhitungan pembobotan dan rating bahwa kekuatan yang potensial dalam kerjasama Sister City Kota Semarang - Kota Brisbane yaitu Bidang perkotaan dan lingkungan, serta kelemahan yang perlu diperbaiki yaitu kemampuan Bahasa Inggris staf Pemerintah Kota Semarang yang masih kurang.

Bidang pembangunan perkotaan dan lingkungan hidup merupakan variabel urgen dalam internal Pemerintah Kota Semarang. Dinas yang membawahi pembangunan perkotaan dan lingkungan hidup antara lain Bappeda Kota Semarang, Dinas Tata Kota dan Perumahan Kota Semarang, Badan Lingkungan Hidup Kota Semarang, serta Dinas Pengelolaan Sumberdaya Air dan Energi Sumberdaya Mineral Kota Semarang. Dinas-dinas tersebut dapat berkoordinasi satu sama lain dalam melaksanakan kegiatan yang berhubungan langsung dengan pembangunan perkotaan dan lingkungan hidup.

Kemampuan Bahasa Inggris Staf Pemerintah Kota Semarang yang kurang merupakan kelemahan internal yang urgen dalam kerjasama Sister City Kota Semarang Kota Brisbane. Penggunaan Bahasa Inggris merupakan salah satu kunci utama berjalannya program-program Sister City Kota Semarang Kota Brisbane. Ketika Australia khususnya Brisbane menggunakan Bahasa Inggris sebagai bahasa sehari-hari sedangkan Pihak Kota Semarang menggunakan Bahasa Indonesia atau Bahasa Jawa ssebagai bahasa sehari-hari. Penggunaan Bahasa Inggris merupakan salah satu bahasa resmi di organisasi internasional seperti Perserikatan Bangsa-Bangsa (PBB) dan Komite Olimpiade Internasional (Creative Commons Attribution, 2015).

Alur ketiga dalam analisis SWOT yaitu matrik Internal - Eksternal yang merupakan alat untuk melihat strategi yang cocok untuk kerjasama Sister City Kota Semarang - Kota Brisbane berdasarkan nilai total faktor internal dan eksternal. Total faktor eksternal (peluang dan ancaman) kerjasama Sister City Kota Semarang - Kota Brisbane yaitu 3.391 dan total faktor internal (kekuatan dan kelemahan) kerjasama Sister City Kota Semarang yaitu 2.939. Berdasarkan nilai kedua faktor, strategi yang cocok untuk kerjasama Sister City Kota Semarang - Kota Brisbane yaitu strategi pertumbuhan dengan konsentrasi integrasi horizontal. Strategi pertumbuhan dalam kerjasama Sister City Kota Semarang - Kota Brisbane yaitu dengan mengembangkan produk baru, menambah kualitas produk atau jasa, dan meningkatkan akses pasar yang lebih besar (Rangkuti, 2016). Integrasi horizontal adalah keadaan dimana sebuah perusahaan mengintegrasikan produksi dan barang atau jasa yang masih ada di dalam satu tahap produksi di dalam rantai suplai, baik melalui ekspansi internal, akuisisi, ataupun merger (Pettinger, 2012). Kedua pemerintah dapat menciptakan inovasi program yang relevan dengan kondisi dua kota beda negara yang dapat dialakukan dengan cara perluasan tujuan program yang dilaksanakan pada kerjasama Sister City Kota Semarang - Kota Brisbane. 
Tabel 2. Analisis SWOT

\begin{tabular}{|c|c|c|}
\hline EKS & $\begin{array}{l}\text { STRENGTH (S) } \\
\text { 1. Dukungan penuh Pemerintah } \\
\text { Kota Semarang } \\
\text { 2. Ruang lingkup kerjasama yang } \\
\text { luas } \\
\text { 3. Bidang pariwisata dan } \\
\text { kebudayaan, pendidikan, iptek, } \\
\text { perkotaan, dan lingkungan } \\
\text { hidup yang potensial } \\
\text { 4. Dukungan dari stakeholder } \\
\text { 5. Sarana dan prasaran Kota } \\
\text { Semarang yang memadai }\end{array}$ & $\begin{array}{l}\text { WEAKNESS (W) } \\
\text { 1. Pendanaan APBD untuk } \\
\text { kerjasama Sister City masih kurang } \\
\text { 2. Perubahan peraturan Otonomi } \\
\text { Daerah } \\
\text { 3.Pergantian pemimpin, } \\
\text { pergantian program } \\
\text { 4. Informasi publik mengenai } \\
\text { Sister City masih kurang } \\
\text { 5. Kemampuan Bahasa Inggris staf } \\
\text { Pemerintah Kota Semarang masih } \\
\text { kurang } \\
\text { 6. Belum efektifnya birokrasi satu } \\
\text { pintu }\end{array}$ \\
\hline $\begin{array}{l}\text { OPPORTUNITY }(\mathrm{O}) \\
\text { 1. Membuka hubungan dan } \\
\text { networking internasional } \\
\text { 2. Saling tukar menukar } \\
\text { informasi } \\
\text { 3. Peningkatan kualitas SDM } \\
\text { 4. Membuka akses kebudayaan } \\
\text { dan pariwisata, pendidikan dan } \\
\text { iptek } \\
\text { 5. Masuknya tawaran baik } \\
\text { berupa bantuan dll }\end{array}$ & $\begin{array}{l}\text { STRATEGI SO } \\
\text { 1. Memberikan dukungan untuk } \\
\text { segala kegiatan positif seperti } \\
\text { hubungan, tawaran kerjasama, } \\
\text { pertukaran pelajar dan lain } \\
\text { sebagainya. } \\
\text { 2. Menggunakan kesempatan } \\
\text { Sister City untuk memanfaatkan } \\
\text { potensi daerah Kota Semarang } \\
\text { dan merefleksi diri Pemerintah } \\
\text { Kota Semarang dalam hal SDM. }\end{array}$ & $\begin{array}{l}\text { STRATEGI WO } \\
\text { 1. Menggunakan kesempatan } \\
\text { keterbukaan hubungan } \\
\text { Internasional untuk mencari } \\
\text { bantuan, seperti adanya bantuan } \\
\text { untuk fasilitas publik, pertukaran } \\
\text { pelajar, kerjasama, belajar Bahasa } \\
\text { Inggris dsb. } \\
\text { 2. Menggunakan kesempatan } \\
\text { untuk meningkatkan informasi } \\
\text { publik, sarpras serta birokrasi }\end{array}$ \\
\hline $\begin{array}{l}\text { THREAT }(\mathrm{T}) \\
\text { 1. Hubungan politik Indonesia - } \\
\text { Australia yang sempat renggang } \\
\text { 2. Wabah flu burung tahun } 2003 \\
\text { 3. Travel Warning dari Australia } \\
\text { 4. Adanya krisis moneter } 1998\end{array}$ & $\begin{array}{l}\text { STRATEGI ST } \\
\text { 1. Menggunakan potensi daerah } \\
\text { terhadap renggangnya } \\
\text { hubungan politik Indonesia } \\
\text { Australia, wabah penyakit, travel } \\
\text { warning, dan keadaan ekonomi. } \\
\text { 2. Mempromosikan lngkungan } \\
\text { Kota Semarang yang aman }\end{array}$ & $\begin{array}{l}\text { STRATEGI WT } \\
\text { 1. Memposisikan Pemerintah Kota } \\
\text { Semarang sebagai Pemerintahan } \\
\text { Daerah, sehingga tidak perlu } \\
\text { terpengaruh dengan isu. } \\
\text { 2. Memperbaiki kelemahan } \\
\text { internal sehingga dapat } \\
\text { menghalau ancaman eksternal. }\end{array}$ \\
\hline
\end{tabular}

(Sumber: Data Primer, 2016) 
Alur keempat dalam analisis SWOT yaitu analisis matrik SWOT digunakan untuk memformulasikan strategi. Analisis SWOT bertujuan untuk mengidentifikasi kekuatan, kelemahan, peluang, dan ancaman yang dihadapi dan dimiliki kerjasama Sister City Kota Semarang - Kota Brisbane. Dengan mengidentifikasikan faktor-faktor tersebut dengan membangun kekuatan, mengurangi kelemahan, memanfaatkan peluang, serta menghalau ancaman (Dyson, 2004). Analisis SWOT menggunakan rating yang kemudian ditotal untuk masing-masing faktor. Alur kelima dalam analisis SWOT yaitu formulasi strategi. Formulasi diposisikan sebagai alur terakhir dalam analisis SWOT karena formulasi hanya dapat dilakukan apabila sudah melakukan analisis EFAS, IFAS, matrik internal - eksternal, dan matrik SWOT.

\section{SIMPULAN}

Simpulan dari hasil analisis dan pembahasan yaitu bahwa kerjasama Sister City Kota Semarang - Kota Brisbane memiliki faktor internal dan eksternal yang dapat mempengaruhi kerjasama tersebut. Faktor internal yang mempengaruhi kerjasama Sister City Kota Semarang - Kota Brisbane yaitu bidang IPTEK dan Pendidikan yang potensial sebagai kekuatan dari kerjasama Sister City Kota Semarang - Kota Brisbane, dan kemampuan Bahasa Inggris Staf Pemerintah Kota Semarang sebagai kelemahan. Faktor eksternal yang mempengaruhi kerjasama Sister City Kota Semarang - Kota Brisbane yaitu peningkatan kualitas SDM, dan hubungan Pemerintah Indonesia dengan Australia yang semoat renggang.

Berdasarkan hasil analisis dan pembahasan di atas, saran yang dapat diberikan adalah memperbaiki kekurangan dalam berbahasa inggris yang tidak hanya dibutuhkan dikalangan pemerintah namun juga masyarakat secara umum, memperkuat bidang IPTEK dan pendidikan seperti mendorong mahasiswa, siswa sekolah, staf, dan pekerja untuk melakukan riset dan pendidikan, memperbesar peluang dengan menambah jumlah bidang kerjasama yang bertujuan untuk meningkatkan kualitas SDM, serta menghindari sesuatu yang personal antara kedua negara karena pada dasaranya kerjasama Sister City yaitu untuk mempromosikan perdamaian, persahabatan, dan pemahaman antar masyarakat dua kota beda negara (BellSouder \& Bredel, 2005). Kerjasama Sister City Kota Semarang - Kota Brisbane perlu adanya campur tangan masyarakat dan pengusaha. Campur tangan masyarakat dan pengusaha diperlukan agar program yang sudah dilaksanakan dapat terus berlanjut..

\section{DAFTAR PUSTAKA}

Bell-Souder, Donald \& Bredel, Shana. 2005. A Study of Sister City Relations. 16 Desember 2005.

Creative Commons Attribution. 2015. Bahasa Inggris. 12 Oktober.

https://id.wikipedia.org/wiki/Bahasa_Inggris\#Status _bahasa tanggal 5 November 2016.

Dyson, Robert G. 2004. "Strategic development and SWOT analysis at the University of Warwick." European Journal of Operational Research. Volume 152: 631640.

Djojohadikusumo, Sumitro. 1991. Perkembangan Pemikiran Ekonomi. Jakarta: Yayasan Obor Indonesia.

Espy, S. 1986. Handbook of Strategic Planning for Nonprofit Organizations. New York: Praeger.

Hidayat, Rizal Arief. (2015). Strategi Pengembangan Industri Kecil Tas Di Kecamatan Jati Kabupaten Kudus. Economics Development Analysis Journal, 3(4). doi:10.15294/edaj.v3i4.3219

Kearns, Kevin P. 1992. "From Comparative Advantage to Damage Control: Clarifying Strategic Issues Using SWOT Analysis." Nonprofit Management \& Leadership. Volume 3(1):3-22. 
Mar'iyah, Chusnul. 2005. Indonesia-Australia: Tantangan dan Kesempatan dalam Hubungan Politik Bilateral. Jakarta: Granit.

Pettinger, Tejvan. 2012. Horizontal Integration. 28 November.

http://www.economicshelp.org/blog/glossary/horiz ontal-integration tanggal 15 November 2016.

Rangkuti, Freddy. 2016. Teknik Membedah Kasus Bisnis Analisis SWOT. Jakarta: Gramedia Pustaka Utama.

Setyawati, Siti Muti'ah \& Agussalim, Dafri. 2015. "Security Complex Indonesia-Australia dan Pengaruhnya terhadap Dinamika Hubungan Kedua Negara". Jurnal Ilmu Sosial dan Ilmu Politik. Vol. 19(2): 111-124.

Sekretariat Daerah Provinsi Jawa Tengah. 2008. Himpunan Peraturan Pemerintah. Jawa Tengah: Sekretariat Daerah Provinsi Jawa Tengah.. 